\title{
A Variable Speed BLDC Motor Drive Fed from A PFC Based Bridgeless Synchronous Buck Boost Converter
}

\author{
Banumathi. S \\ Department of Electrical and Electronics Engg, M. Kumarasamy College of Engineering, Karur, Tamilnadu, India
}

\begin{abstract}
A power factor correction (PFC) based Synchronous buck- boost converter fed brushless DC motor drive and an economic solution for low power applications is presented in this paper. A voltage source inverter which comprises low switching losses is fed from the dc link voltage is used to control the speed of BLDC motor. The dc link voltage is controlled by a synchronous buck boost converter which receives power from a diode bridge rectifier unit. Analysis of PFC synchronous buck- boost converter is made and its performance was assessed under continuous and discontinuous modes of operation. A BLDC motor is well known for its low maintenance, good efficiency and higher price. So reducing the cost of the BLDC motor has become essential. Pulse Width Modulation (PWM) technique has been broadly used to control power converter circuits. The results reveals that the harmonics in the output voltage and current has been reduced compare to buck boost converter.
\end{abstract}

Keywords: Synchronous buck- boost converter, power factor correction (PFC), Brushless DC motor, Pulse Width Modulation (PWM).

\section{INTRODUCTION}

The stator of BLDC motor consisting of concentrated three phase windings and rotor is made up of permanent magnet setup. The rotor doesn't contain any mechanical parts like commutator or brushe [1]. The conventional motor with commutator and brushes is having sparking, wear and tear are eradicated by using BLDC motors [2]. The commutation process in BLDC motor is done with the help of hall rotor position senor, so the motor is also called as electrically commutated motor.

Generally permanent magnet motors are the appropriate choice for critical appliances in key applications like actuators, aerospace, tool drives and actuators[3]. Because these type of systems needs servo system and reliable operation[4]. In this paper PMBLDC motor which can supply highest torque for large acceleration and deceleration rates is assessed for its concert with refer to the parameters of the motor.

The design of PFC converter make it to function in two modes one is continuous conduction mode (CCM) and the other one is discontinuous conduction mode (DCM). The design of PFC converter directly affects the overall cost of the system because of the rating of the components used in the system. So care should be taken before selecting the mode. The continuous conduction mode (CCM) needs to sense supply voltage and dc link voltage and current at the input end for PFC function. In CCM the current flow through the inductor or the voltage across the capacitor is continuous and cost required is not high. However, DCM needs one voltage sensor to sense the voltage of dc link voltage control and intrinsic PFC is obtained at the ac mains. But the cost of PFC converter becomes very high.

Therefore DCM is chosen for low power application. A pulse width-modulated voltage source inverter (PWMVSI) $[5,6]$ with a constant dc link voltage is conventionally used to control the speed of BLDC motor with PFC. This leads to high switching losses in VSI because the switching losses are nothing but a square of switching frequency. Since the BLDC motor speed is directly proportional to the supplied dc link voltage, the speed control of BLDC motor can be attained by changing the dc link voltage of VSI[7]. This method in such a way permits the fundamental frequency switching of VSI (i.e. Electronic commutation) and propose reduced switching losses.

The proposed system is applicable to the speed control of BLDC motor with particular ratings and is not suitable for all BLDC motor ratings. For speed control PID controller can alone be used not $\mathrm{P}$ or PI controller [8].

A bridge rectifier with diode gives dc supply is the input to the Synchronous buck boost converter working in a discontinuous conduction mode (DCM) is employed for control of dc link voltage with the ac mains of unity power factor. The unity power factor is achieved at ac mains side by 1 phase power factor correction converters are used to achieve unity power factor at ac mains. Analysis of PFC synchronous buck- boost converter is made and its performance was assessed under continuous and discontinuous modes of operation. 
Vol. 5, Issue 2, February 2017

\section{SYNCHRONOUS BUCK BOOST CONVERTER}

In a conventional power factor correction converter fed BLDC motor the dc link voltage of the VSI is kept constant and the speed of the motor is controlled by varying the duty ratio of high frequency PWM signal. Since the switching losses are proportional to the square of the frequency, the amount of losses in VSI are considerable. Since the switching frequency is $500 \mathrm{KHz}$ in buck boost converter, the switching loss is high. This in turn increases the duty ratio and draws more pulsed current from the source. This current flow through the semiconductor device is higher than the load current flow through the device and the input inductor. This cause more induction losses in the semiconductor devices and fairly low efficiency.

The proposed system can able to change the supply voltage to either higher value or low voltage value without any change in its polarity. For any value of input voltage ranges from $2.4 \mathrm{~V}$ to $3.4 \mathrm{~V}$ the controller provides output voltage range of $0.4 \mathrm{~V}$ to $4.0 \mathrm{~V}$ with the load current value upto $0.65 \mathrm{~A}$. In this work a four switch synchronous buck boost converter with single inductor is used. The advantages of this converter is same as two switch synchronous converter and the duty ratio at all times is higher than 0.5. In power management circuits and for handy applications buck-boost converters are mostly used. Inverting buck-boost converters and Cuk converters [9] are able to convert supply voltages to both high and low voltages. The figure 1 shown below is circuit diagram of non inverting synchronous buck boost converter.

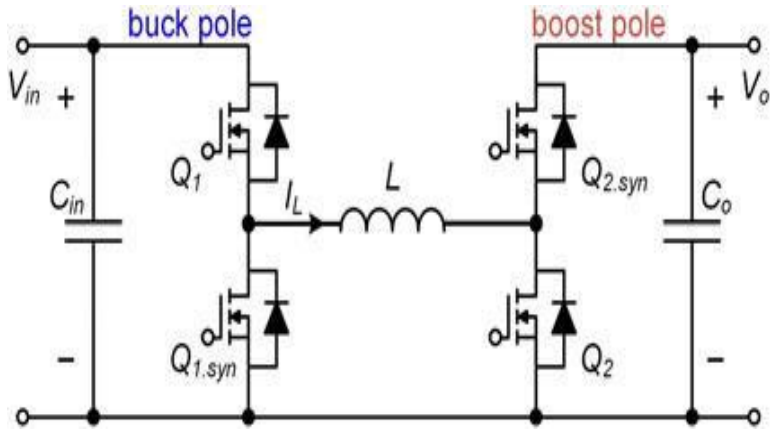

Fig. 1 Circuit diagram for synchronous buck-boost converter

\section{PFC BASED BRIDGELESS SYNCHRONOUS BUCK-BOOST CONVERTER}

The block diagram for synchronous buck-boost converter is shown in the figure 2 . The simulink diagram of the proposed system is shown in the figure 3. Ac supply is given to the step down transformer. In this $230 \mathrm{~V}$ is converted into $24 \mathrm{~V}$. Rectifier circuit is followed by the step down transformer. It converted AC voltage into DC voltage. In order to reduce the harmonics the filter circuit is used. The pure dc voltage is fed into the synchronous buck boost converter.

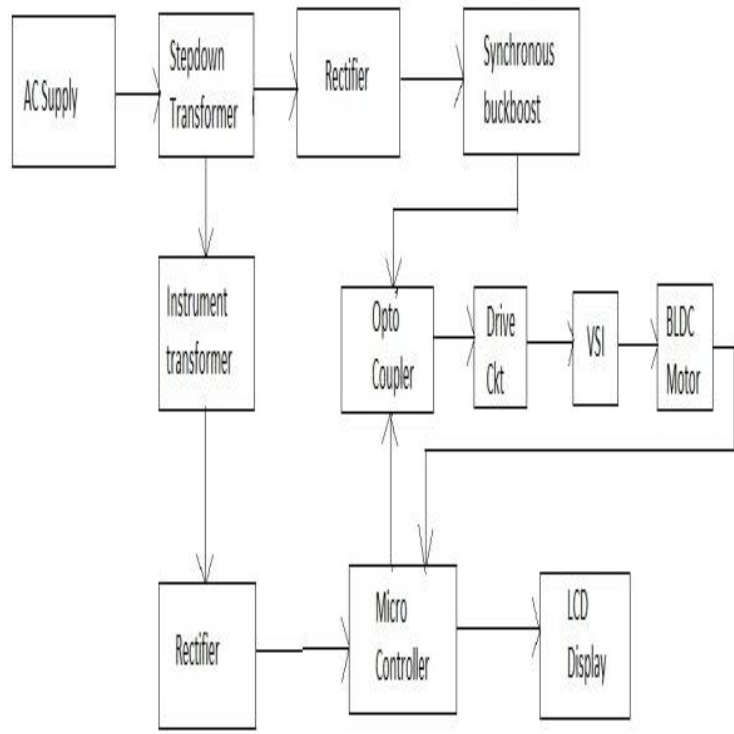

Fig. 2 Block diagram for FC based Bridgeless synchronous buck-boost converter

In our project $24 \mathrm{~V}$ is boost up into $28 \mathrm{~V}$ using this converter. This signal is given to the optocoupler. Optocoupler is used to pass the electric signal between two circuits using light source to give electrical isolation between them. This light signal is fed into the driver circuit. It is used for the purpose of smooth switching.

Voltage regulator IC used here includes variety of functions of generally used ICs. The regulator IC comprises of circuits for source reference, control tool, comparator amplifier and protection against over load all in one IC. The dc voltage is converted into ac voltage by VSI because the BLDC motor requires ac voltage. Corresponding to power rating from milliwatts to 10 watts the regulators can be chosen to drive the load with load current from hundred to ten milliamperes.

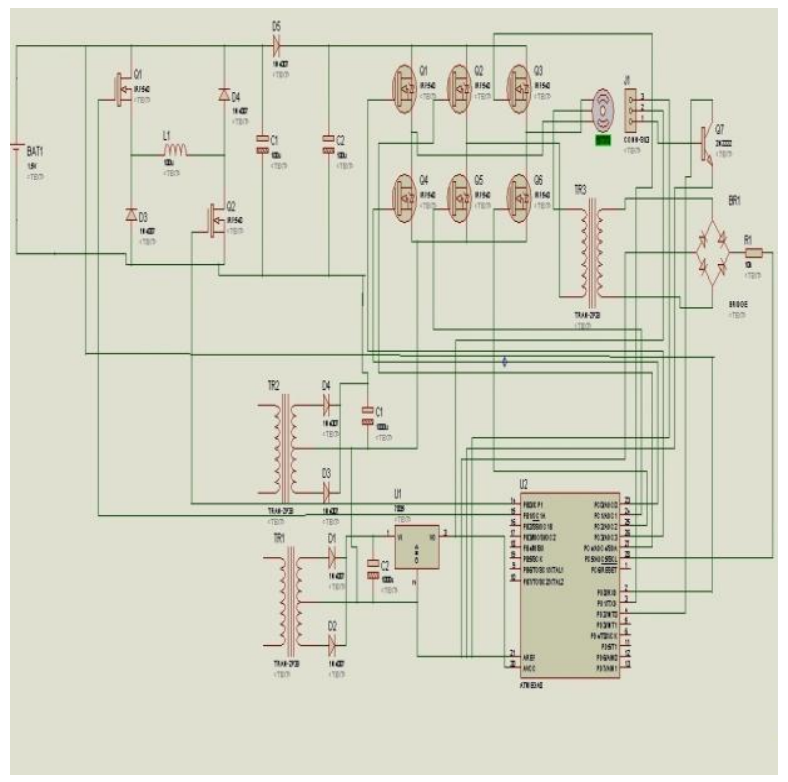

Fig 3 Simulink diagram for proposed system 
Vol. 5, Issue 2, February 2017

\section{MODES OF OPERATION IN VSI}

A complete switching cycle for one entire positive half cycle of supply voltage consists of three modes of operation. The simulink diagram for proposed voltage source inverter system is given in the figure 4 .

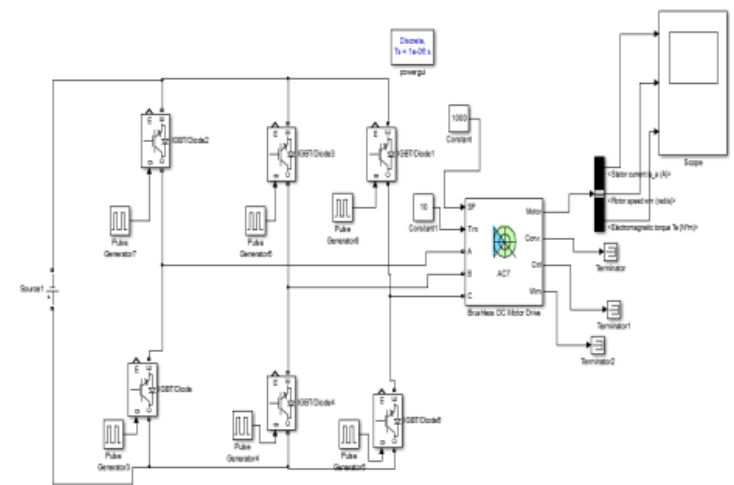

Fig 4 Simulink diagram for proposed voltage source inverter system

A. Mode I: During mode I, when the switch sw2 triggers, current will flow through the inductor and the energy stored in the inductor Li2. The input side circuit is completed through the diode Dp. The dc link capacitor Cd discharges through VSI fed BLDC motor. The figure 5 for mode I operation is shown below.

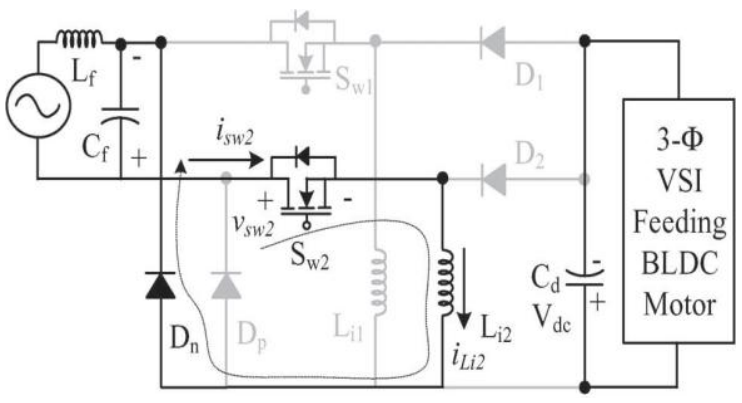

Fig 5 Mode I operation

B. Mode II: The mode II operation is shown in the figure 6 . Here switch 2 is turned off and the energy stored in the inductor $\mathrm{Li} 2$ is completely discharges to capacitor $\mathrm{Cd}$ till the current flow through the inductor becomes zero.

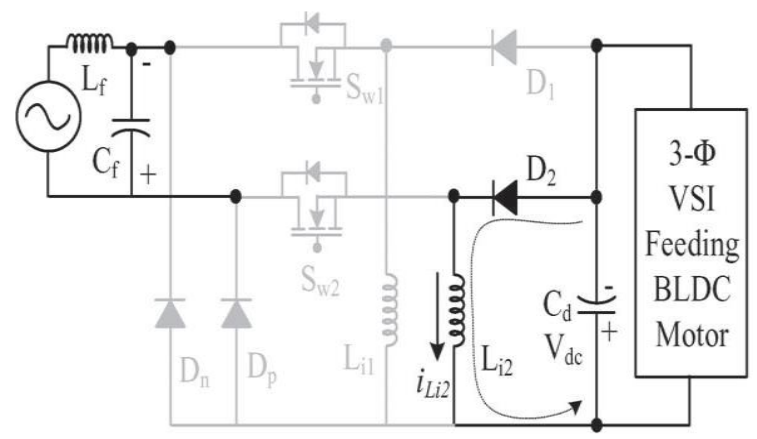

Fig 6 Mode II operation
C. Mode III: Inductor Li 2 discharges its energy completely so the current flow through the inductor has become zero. The inductor goes into the discontinuous conduction mode. In this mode III no switch or diode are conducting mode. Dc link capacitor Cd delivers energy to the BLDC motor through VSI. So the voltage across the capacitor starts decreasing. The second cycle of operation begins when Sw1 gets triggering pulse. The mode III operation is shown in Figure 7.

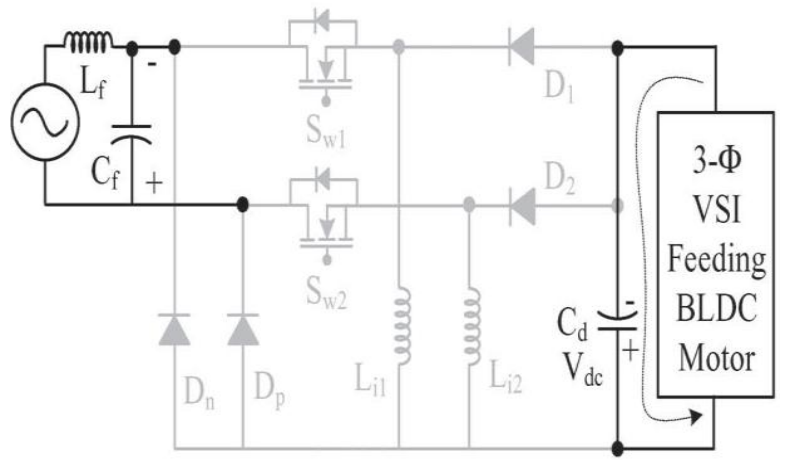

Fig 7 Mode III operation

\section{RESULT AND DISCUSSION}

A MOSFET operates with high frequency is used in the bridgeless Synchronous buck-boost converter for PFC and voltage control, where as in VSI circuit insulated gate bipolar transistors (IGBT) are used to work in low frequency. The electrical commutation takes place in BLDC motor and to reduce switching losses the IGBT of VSI is operated in fundamental frequency switching mode. The hard ware of the proposed system is shown in figure 8. A Synchronous buck-boost converter is premeditated to function in all 3 discontinuous mode and continuous mode of operation. Then the performance of the proposed system is assessed for a broad voltage range control with unity power factor at ac mains.

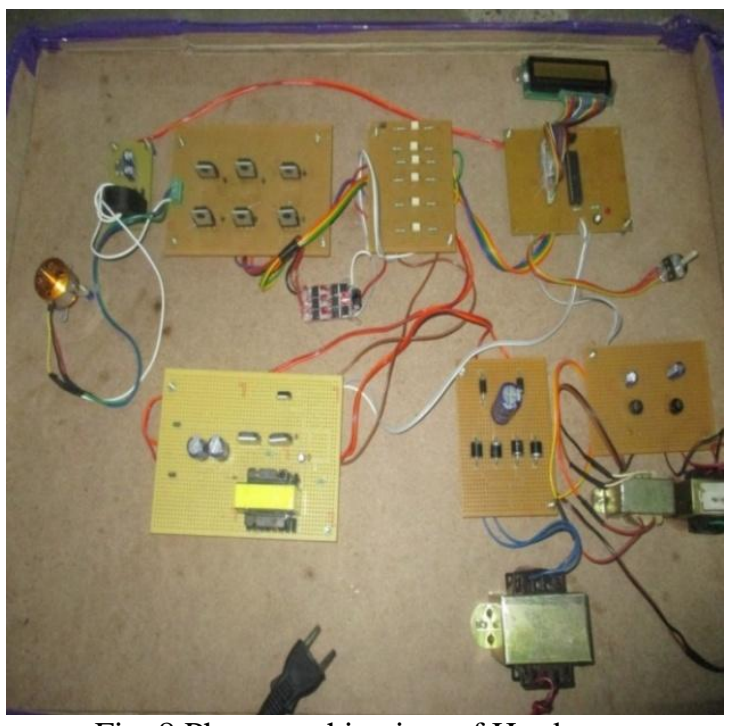

Fig. 8 Photographic view of Hardware 
The proposed algorithm controls each pole of the converter to reduce the inductor current ripple. The hardware output is shown in the figure 9. It shows that when there is a conduction of alternate inductor for positive and negative cycle of supply voltage the voltage applied across the BLDC motor has ups and downs. When the VSI of the circuit supplied with only one inductor at that time it can able to supply stable voltage .
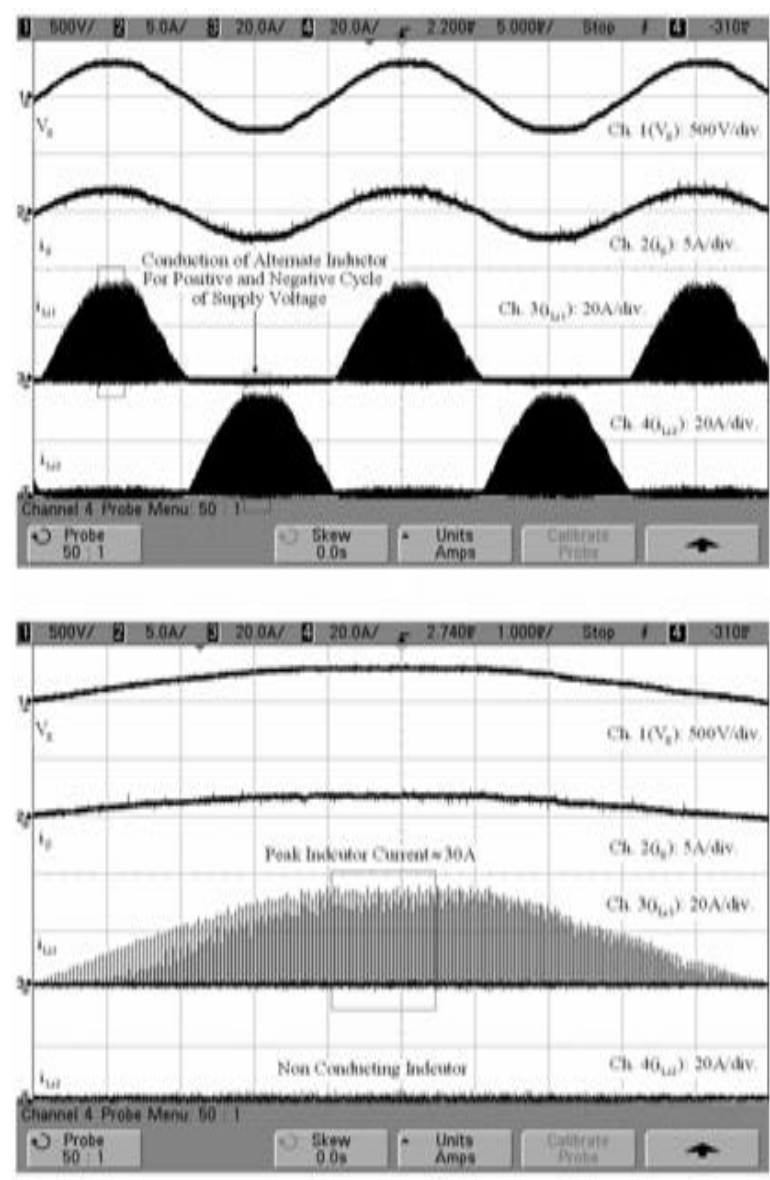

Fig.9 Hardware output waveform

\section{CONCLUSION}

A power factor correction (PFC) based Synchronous buckboost converter fed BLDC motor drive is discussed in this paper. An economic solution for low power appliances is suggested in this work by applying discontinuous mode of operation for PFC converter. A voltage source inverter which comprises low switching losses is used to control the speed of BLDC motor. Analysis of PFC synchronous buck- boost converter is made and its performance was assessed under continuous and discontinuous modes of operation. From the results it is clear that the increase in voltage level improves the performance characteristics of the BLDC motor. The harmonics in the output voltage and current has been reduced compare to buck boost converter.

\section{REFERENCES}

11] Y. Chen, C. Chiu, Y. Jhang, Z. Tang, and R. Liang, "A driver for the Single phase brushless dc fan motor with hybrid winding structure," IEEE Trans. Ind. Electron., vol. 60, no. 10, pp. 43694375, Oct. 2013.

[2] X. Huang, A. Goodman, C. Gerada, Y. Fang, and Q. Lu, “A single sided matrix converter drive for a brushless dc Motor in aerospace applications," IEEE Trans. Ind. Electron. vol. 59, no. 9, pp. 3542-3552, Sep. 2012.

[3] J. Moreno, M. E. Ortuzar, and J. W. Dixon, "Energy-management system for a hybrid electric vehicle, using ultracapacitors and Neural networks," IEEE Trans. Ind. Electron., vol. 53, no. 2, pp. 614-623, Apr. 2006.

[4] P. Pillay and R. Krishnan, "Modeling of permanent magnet motor drives,'IEEE Trans. Ind. Electron., vol. 35, no. 4, pp. 537-541, Nov. 1988.

[5] Karthikeyan, R., Pandian, S.C., An efficient multilevel inverter system for reducing THD with space vector modulation. Int. J. Comput. Appl. 23 (2), 11-15, 2011.

[6] Sundararaju K., A. Nirmal Kumar, "Cascaded Control of Multilevel Converter based STATCOM for Power System Compensation of Load Variation"International Journal of Computer Applications (0975 - 8887) Volume 40- No.5, Pp30-35, 2012.

[7] C. L. Xia, Permanent Magnet Brushless DC Motor Drives and Controls. Hoboken, NJ, USA: Wiley, 2012.

[8] J. Gouthaman, R. Bharathwajanprabhu, and A. Srikanth. Automated urban drinking water supply control and water theft identifi- cation system. In Students' Technology Symposium (TechSym), 2011 IEEE, pages $87-91$, jan. 2011.

[9] S. Singh and B. Singh, "A voltage-controlled PFC Cuk converter based PMBLDCM drive for air-conditioners," IEEE Trans. Ind. Appl., vol. 48, no. 2, pp. 832-838, Mar./Apr. 2012.

[10] Rathinam A, Karthikeyan T, and Ramani K , Reduction of Components in New Family of Diode Clamp Multilevel Inverter Ordeal to Induction Motor, Journal of Semiconductor Technology And Science, Vol.16, No.1, February, 2016, Pp 58-69. 